\title{
Size Effect on Recycled Concrete Strength and Its Prediction Model Using Standard Neutrosophic Number
}

\author{
X. Peng $\mathbb{D}^{1,2}$ Q. W. Yang, ${ }^{1,2}$ and F. J. Qin $\mathbb{D}^{3}$ \\ ${ }^{1}$ School of Civil and Transportation Engineering, Ningbo University of Technology, Ningbo 315211, China \\ ${ }^{2}$ Engineering Research Center of Industrial Construction in Civil Engineering of Zhejiang, Ningbo University of Technology, \\ Chongqing, China \\ ${ }^{3}$ Key Laboratory of New Technology for Construction of Cities in Mountain Area, Ministry of Education, \\ School of Civil Engineering, Chongqing University, Chongqing 400045, China
}

Correspondence should be addressed to F. J. Qin; qinfengjiang@cqu.edu.cn

Received 29 December 2020; Revised 28 January 2021; Accepted 27 February 2021; Published 9 March 2021

Academic Editor: Lingzhi Li

Copyright ( $\odot 2021$ X. Peng et al. This is an open access article distributed under the Creative Commons Attribution License, which permits unrestricted use, distribution, and reproduction in any medium, provided the original work is properly cited.

In recent years, research on recycled aggregate concrete has become a hot issue in the field of civil engineering. This paper mainly studies the size effects on compressive and tensile strengths of the recycled aggregate concrete. Firstly, four sets of recycled concrete cube specimens with different sizes are produced in the laboratory. Secondly, the experiments on compressive and tensile strengths are carried out to obtain the rules of the strength value with the change of the specimen size. Thirdly, a standard neutrosophic number is proposed and used in modelling the size effect law more reasonably. According to the experimental results, it was found that the compressive and tensile strengths of recycled concrete both have obvious size effects. In general, the strength value decreases gradually with the increase of specimen size. Using the standard neutrosophic number, the proposed new formula on size effect law is more suitable for tackling the indeterminacy in the experimental data. It has been shown that the size effect law based on the standard neutrosophic number is more realistic than the existing size effect law. The results may be useful for the engineering application of the recycled concrete and can be extended to other types of size effect laws in the future.

\section{Introduction}

Demanding by environmental protection, some research on recycled aggregate concrete (RAC) has been carried on in many countries in recent years. At present, the research on recycled aggregate concrete mainly focuses on its mechanical properties or durability. Barhmaiah et al. [1] investigated the effect of recycled aggregate on strength of concrete and the results were compared with virgin aggregate concrete. $\mathrm{Wu}$ and Jin [2] studied the compressive fatigue behavior of compound concrete containing demolished concrete lumps and recycled aggregate concrete. It was found that satisfactory compressive strength can be attained when the total waste content in RLAC reaches $54.6 \%$. Akono et al. [3] investigated the basic creep and fracture response of fine recycled aggregate concrete using nanoscale mechanical characterization modules integrated with nonlinear micromechanical modelling and machine learning methods. It has been shown that the fracture toughness of fine recycled aggregate concrete is $8 \%$ lower than that of plain concrete. Sasanipour et al. [4] investigated the effects of the surface pretreatment method by soaking recycled concrete aggregates in silica fume slurry on the mechanical and durability properties of recycled aggregate concrete. Results revealed that using pretreated recycled aggregates significantly improved the durability properties of mixes especially chloride ion penetration and electrical resistivity. Zhu et al. [5] investigate the long-term performance of recycled aggregate concrete beams for a period of 3045 days and the bending behavior of test beams after the sustained load is removed. It was found that the RAC beams exhibit more significant stiffness degradation characteristics in the flexural test. Mi et al. [6] studied the influences of the compressive strength ratio between original concrete and recycled aggregate 
concrete on the slump, compressive strength, and carbonation resistance of recycled aggregate concrete. Results revealed that adjusting the compressive strength ratio can furnish different slump, compressive strength, and carbonation depth values, while also reducing mortar inhomogeneities. Wang et al. [7] studied the influences and mechanisms of the single and coupled effect of carbonation, dry-wet cycles, and freeze-thaw cycles on the durability of three types of recycled aggregate concrete. The results showed that carbonation and dry-wet cycles can improve the pore tortuosity and reduce the connectivity of pores.

As is well known, the strength of quasibrittle materials like concrete and rock is size dependent due to the heterogeneity [8-11]. Generally, the geometrically similar samples will not behave similarly for different sizes; this is named as size effect (or scale effect). In the past few decades, the size effect problem has been widely investigated by many scientists and engineers. Overall, the existing scale effect laws can be divided into three types: (1) statistical size effect $[12,13],(2)$ energetic size effect [14-18], and (3) fractal size effect $[19,20]$. Additionally, some researchers used the artificial neural network (ANN) technique to forecast the size effect of concrete strength [21,22]. In these laws, the energetic size effect proposed by Bazant [11,14-18,23-29] has been shown very effective and promising for those quasibrittle materials. Although much progress has been made in the size effect mechanism, much further research is needed for new type concrete and recycled aggregate concrete. On the other hand, it is well known that most of the physical quantities in engineering practice cannot be correctly expressed by using crisp numbers due to the limitation of experimental test techniques and the complexity of objective things. Apparently, the tested concrete strength is just the physical quantity that always fluctuates within a certain range. It is difficult to express these strength parameters only by using determined values. As a result, it is very necessary to extend the existing size effect law to tackle the indeterminacy in the tested strength data.

To handle indeterminate information in practice, Smarandache [30-32] presented the concept of a neutrosophic number for the first time. The neutrosophic number, which consists of a determinate part and an indeterminate part, is very suitable for the expression of data with indeterminacy. However, little progress has been made for handling indeterminate problems by neutrosophic numbers in scientific and engineering areas in the past two decades. Recently, Ye $[33,34]$ used the neutrosophic number as a tool for solving the group decision-making and fault diagnosis problems, respectively. It has been shown that the neutrosophic number can effectively deal with real problems with indeterminacy. In this paper, a standard neutrosophic number is firstly proposed for the improvement of the multiplication of neutrosophic numbers to a certain extent. And then the standard neutrosophic number is used to modify the size effect laws on the compressive and tensile strengths of the recycled aggregate concrete. The proposed size effect law based on the standard neutrosophic number provides a simple and effective way to tackle the indeterminacy in the strength parameters.
The presentation of this work is organized as follows: Section 2 presents the size effect experimental scheme and material properties used in the recycled aggregate concrete. Section 3 gives the testing results of the compressive and tensile strengths for the cube specimens. In Section 4, the neutrosophic number is briefly reviewed and a standard neutrosophic number is developed and used to improve the size effect law for reflecting the indeterminacy in data. Finally, the conclusions of this work are summarized in Section 5 .

\section{Experimental Scheme and Material Properties}

As shown in Figure 1, four sets of recycled concrete cube specimens with different sizes are designed to investigate the strength-size effect. Each group has six test blocks (three for compressive test, three for splitting tensile test) and the total number of these specimens is 24 . The side lengths of these cube specimens are $70 \mathrm{~mm}, 100 \mathrm{~mm}, 150 \mathrm{~mm}$, and $200 \mathrm{~mm}$, respectively.

Tables 1-3 present the main material properties of the cement, fine aggregate, and recycled coarse aggregate used in this experiment, respectively. The cement is the ordinary PM32.5 Portland cement and the fine aggregate is the natural river sand. The recycled coarse aggregate as shown in Figure 2 is manufactured from the waste concrete in the process of old building dismantling.

Table 4 gives the mixture ratio, water-cement ratio, and replacement ratio of recycled coarse aggregate used in the experiment. In all these factors, the mixture ratio design is the key factor to determine the strength grade of concrete.

Finally, these recycled concrete cube specimens as shown in Figure 3 are produced in the laboratory. After curing in water for 28 days, the compressive and splitting tensile strength tests are carried out.

\section{Experiment Test and Result Analysis}

Figure 4 presents the experiment equipment used for the compressive and splitting tensile strengths, respectively. The experiment equipment is called the STYE-3000E automatic pressure testing machine. The detailed testing steps strictly complied with the norms of "standard for test methods of mechanical properties of ordinary concrete (GB/T 50081-2002)" [35].

Table 5 and Figure 5 present the test results of the compressive strengths, respectively. Table 6 and Figure 6 present the test results of the splitting tensile strengths, respectively.

From Tables 5 and 6, it has been shown that the compressive and tensile strengths of recycled concrete both have obvious size effects. In general, the mean value of strength decreases gradually with the increase of specimen size. Taking the specimens with a side length of $70 \mathrm{~mm}$ as the reference group, the degrees of size effect for other groups can be computed as 

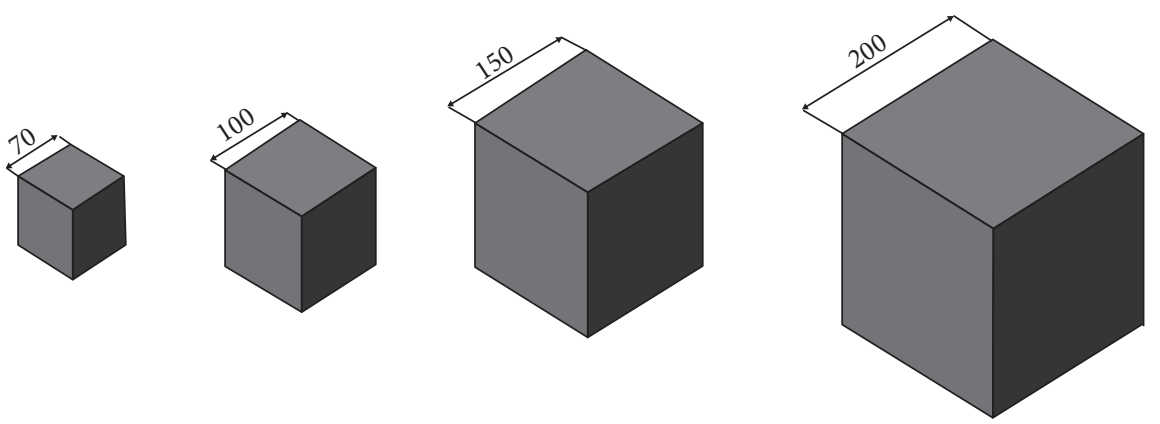

FIgURe 1: Cube specimen geometry size (unit: mm).

TABLE 1: Main properties of PM32.5 cement.

\begin{tabular}{lccc}
\hline Number & & & \\
\hline 1 & & Properties & \\
2 & Sensity $\left(\mathrm{kg} / \mathrm{m}^{3}\right)$ & 3051 \\
2 & & Initial set $/ \mathrm{min}$ & 172 \\
& & Final set/min & 225 \\
3 & Compressive strength & $3 \mathrm{~d} / \mathrm{MPa}$ & 17.8 \\
& & $28 \mathrm{~d} / \mathrm{MPa}$ & 35 \\
4 & Rupture strength & $3 \mathrm{~d} / \mathrm{MPa}$ & 3.9 \\
\end{tabular}

TABLE 2: Main properties of fine aggregate.

\begin{tabular}{lcc}
\hline Number & Properties & Condition or value \\
\hline 1 & Fine aggregate & River sand \\
2 & Grain diameter $/ \mathrm{mm}$ & $<5$ \\
3 & Apparent density $\left(\mathrm{kg} / \mathrm{m}^{3}\right)$ & 2548 \\
4 & Bulk density $\left(\mathrm{kg} / \mathrm{m}^{3}\right)$ & 1211 \\
5 & Water ratio $(\%)$ & 6.8 \\
6 & Gradation & III \\
7 & Modulus of fineness $\mu_{f}$ & 1.83 \\
8 & Water absorption $(\%)$ & 2.9 \\
\hline
\end{tabular}

TABLE 3: Main properties of recycled coarse aggregate.

\begin{tabular}{lcc}
\hline Number & Properties & Value \\
\hline 1 & Apparent density $\left(\mathrm{kg} / \mathrm{m}^{3}\right)$ & 2481 \\
2 & Bulk density $\left(\mathrm{kg} / \mathrm{m}^{3}\right)$ & 1240 \\
3 & Water absorption $(\%)$ & 6.3 \\
4 & Water ratio (\%) & 2.2 \\
5 & Crush value index $(\%)$ & 19.9 \\
6 & Cavity ratio (\%) & 5.7 \\
7 & Porosity (\%) & 51.0 \\
8 & Incubation rate $(\%)$ & 42.9 \\
\hline
\end{tabular}

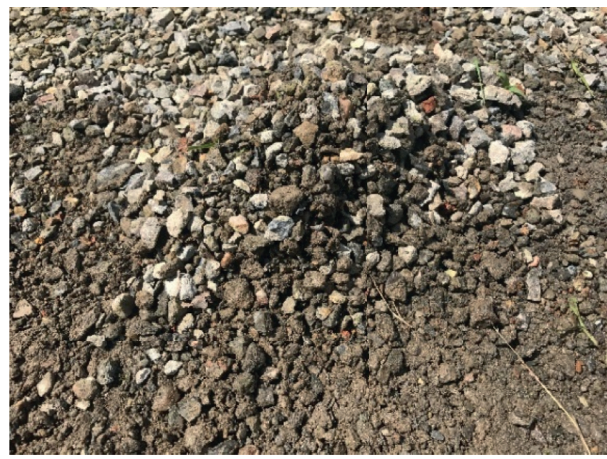

(a)

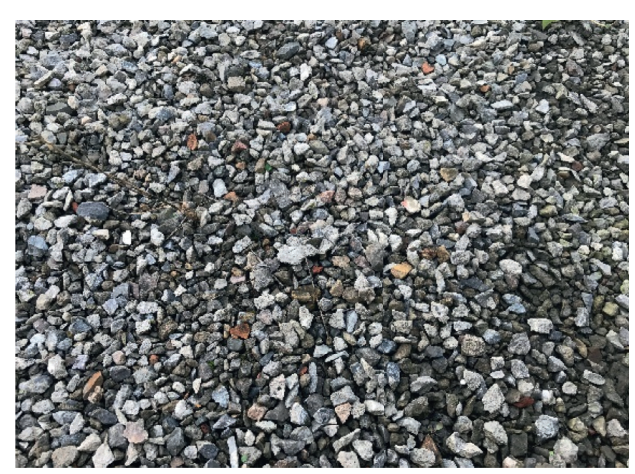

(b)

Figure 2: Recycled coarse aggregate. 
TABLE 4: The mixture ratio, water-cement ratio, and replacement ratio of recycled coarse aggregate.

\begin{tabular}{|c|c|c|c|}
\hline Number & & Properties & Value \\
\hline 1 & & Water-cement ratio & 0.37 \\
\hline 2 & & ent ratio of recycled coarse aggregate & $100 \%$ \\
\hline \multirow{4}{*}{3} & \multirow{4}{*}{ Material consumption } & Cement $(\mathrm{kg})$ & 71.984 \\
\hline & & Water $(\mathrm{kg})$ & 27.210 \\
\hline & & Fine aggregate $(\mathrm{kg})$ & 61.037 \\
\hline & & Recycled coarse aggregate $(\mathrm{kg})$ & 103.843 \\
\hline 4 & The mixture ratio & Cement: water: fine aggregate: recycled coarse aggregate & $1: 0.378: 0.848: 1.443$ \\
\hline
\end{tabular}

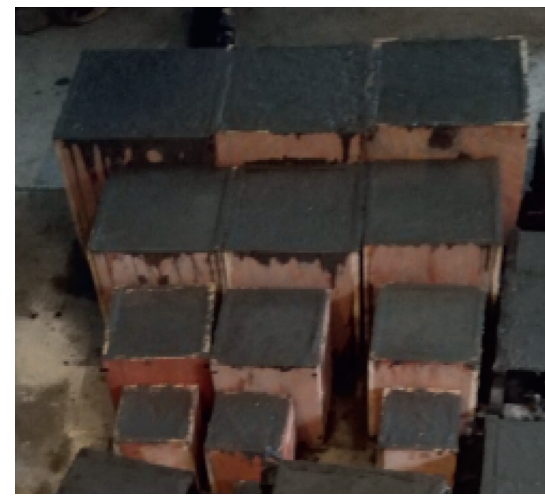

(a)

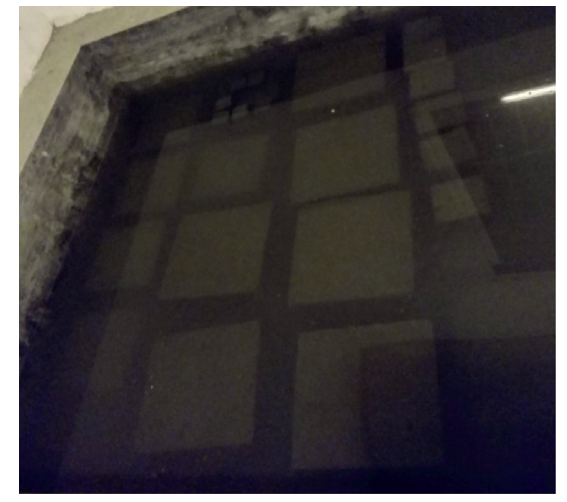

(b)

FIgURE 3: Recycled concrete cube specimens.

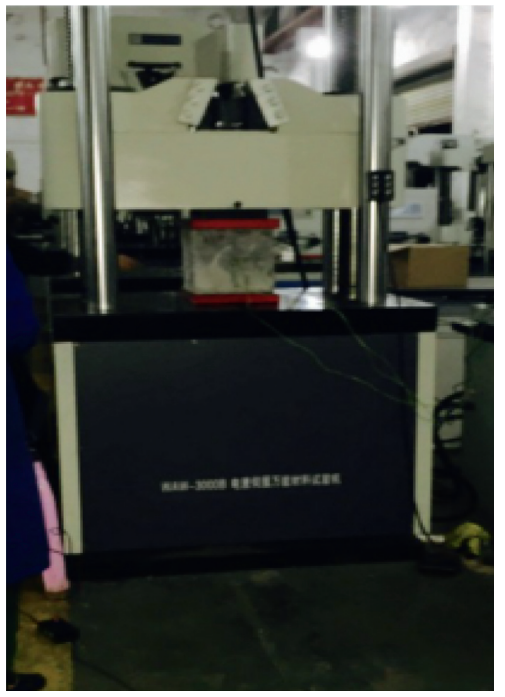

(a)

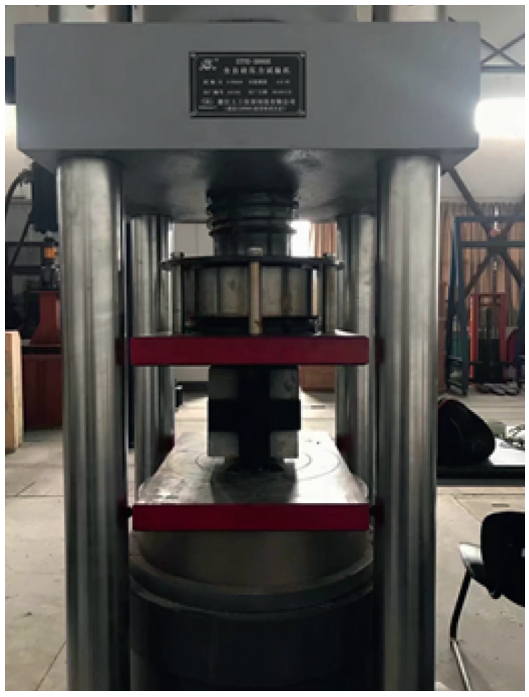

(b)

FIgURE 4: Experiment equipment for compressive and splitting tensile strengths.

TABLE 5: Mean values and standard deviations of compressive strengths.

\begin{tabular}{lcccccc}
\hline \multirow{2}{*}{ Side length of cube specimen $(\mathrm{mm})$} & \multicolumn{4}{c}{ Compressive strength $\left(S_{c}\right)$} & $(\mathrm{MPa})$ & \multicolumn{2}{c}{ Standard deviation $(\delta)$} & Coefficient of variation \\
& Block 1 & Block 2 & Block 3 & Mean value & & \\
\hline 70 & 32.250 & 52.189 & 55.415 & $\mathbf{4 6 . 6 1 8}$ & 10.244 & 0.220 \\
100 & 34.618 & 32.401 & 33.509 & $\mathbf{3 3 . 5 1 0}$ & 0.905 & 0.027 \\
150 & 36.580 & 28.586 & 30.449 & $\mathbf{3 1 . 8 7 1}$ & 3.415 & 0.107 \\
200 & 36.443 & 24.047 & 27.491 & $\mathbf{2 9 . 3 2 7}$ & 5.224 & 0.178 \\
\hline
\end{tabular}




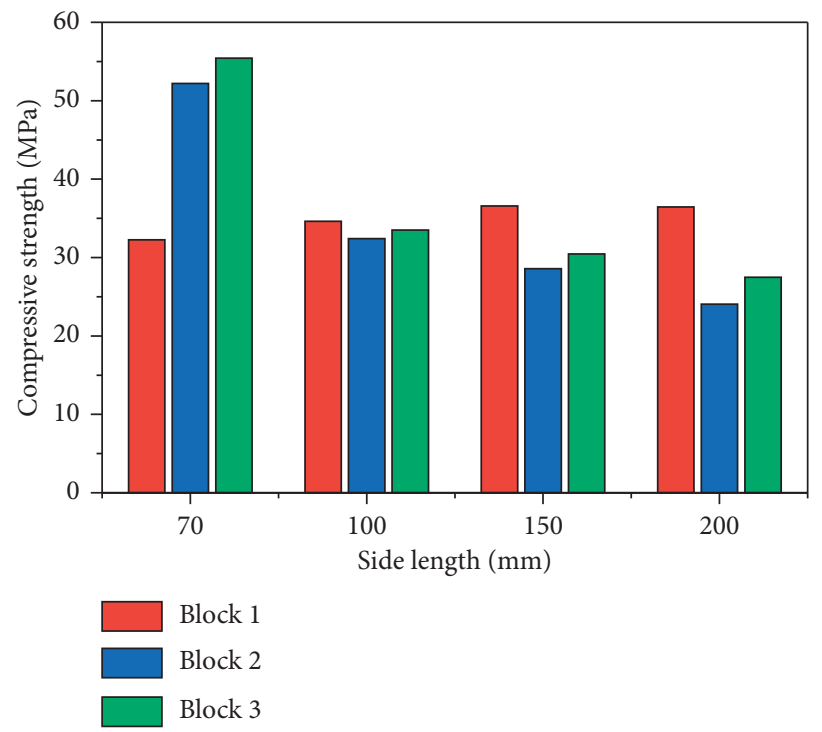

FIgURE 5: Compressive strength values of cube specimens.

TABLE 6: Mean values and standard deviations of splitting tensile strength values.

\begin{tabular}{lcccccc}
\hline \multirow{2}{*}{ Side length of cube specimen $(\mathrm{mm})$} & \multicolumn{3}{c}{ Splitting tensile strength $\left(S_{t}\right)(\mathrm{MPa})$} & \multirow{2}{*}{ Standard deviation $(\delta)$} & Coefficient of variation \\
& Block 1 & Block 2 & Block 3 & Mean value & & 0.255 \\
\hline 70 & 4.657 & 5.838 & 3.034 & $\mathbf{4 . 5 1 0}$ & 1.149 & 0.194 \\
100 & 2.882 & 4.695 & 4.158 & $\mathbf{3 . 9 1 2}$ & 0.760 & 0.173 \\
150 & 4.304 & 2.919 & 3.188 & $\mathbf{3 . 4 7 0}$ & 0.600 & 0.155 \\
\hline
\end{tabular}

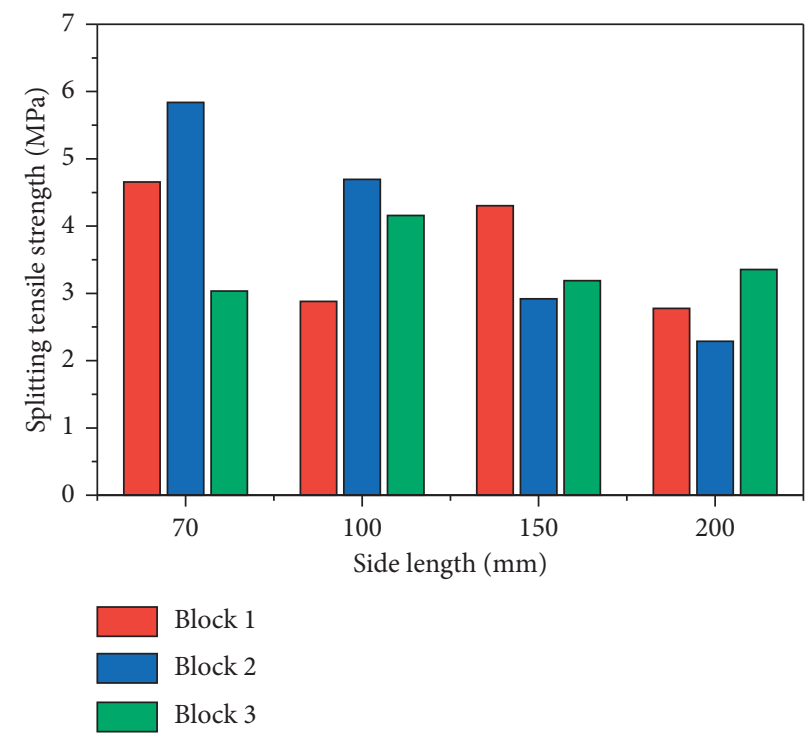

Figure 6: Splitting tensile strength values of cube specimens. 


$$
\begin{aligned}
& D_{c, 100}=\frac{46.618-33.51}{46.618} \times 100 \%=28.12 \%, \\
& D_{c, 150}=\frac{46.618-31.871}{46.618} \times 100 \%=31.63 \%, \\
& D_{c, 200}=\frac{46.618-29.327}{46.618} \times 100 \%=37.09 \%, \\
& D_{t, 100}=\frac{4.51-3.912}{4.51} \times 100 \%=13.26 \%, \\
& D_{t, 150}=\frac{4.51-3.47}{4.51} \times 100 \%=23.06 \%, \\
& D_{t, 200}=\frac{4.51-2.806}{4.51} \times 100 \%=37.78 \% .
\end{aligned}
$$

From Tables 5 and 6, it was found that the discreteness of data of the compressive strength is far greater than that of the splitting tensile strength. The possible reasons for this phenomenon are as follows: (1) the compressive strength of the test block is closely related to that of recycled aggregate. It is known that the compressive strengths of recycled aggregates in different specimens fluctuate greatly. This leads to the great discreteness of compressive strength data. (2) The splitting tensile strength is mainly affected by the cohesive force between cement and aggregate. At this point, there is no obvious difference for different recycled aggregates.

\section{Size Effect Law Using the Standard Neutrosophic Number}

4.1. The Neutrosophic Number and Its Standard Form. As stated before, the above strength values always contain some randomness due to the limitation of experimental techniques and the complexity of objective things. In order to better describe the randomness in data, the neutrosophic number will be introduced in this work to describe strength since it is a powerful tool for the expression of data with indeterminacy. Smarandache defined a neutrosophic number for the first time in neutrosophic probability [30-32]. A neutrosophic number, which can be divided into a determinate part and an indeterminate part, is expressed as

$$
N=x+y I
$$

in which $x$ and $y$ are real numbers, $I$ is indeterminacy, such that $I^{2}=I, 0 \cdot I=0$, and $I / I=$ undefined. In a sense, a neutrosophic number can be treated as an interval number. For example, assume that a neutrosophic number is $N=2+3 I$, where $I \in[0,0.5]$. Then, it is equivalent to an interval number $N=[1.7,2.3]$. Compared with the interval number, the advantages of the neutrosophic number are as follows: (1) The neutrosophic number more highlights the determinate part, which is the common concerned point in engineering application. (2) The neutrosophic number is similar to the imaginary number in form. Thus, the operational rule of the neutrosophic number is more convenient to implement. Letting $N_{1}=x_{1}+y_{1} I$ and $N_{2}=x_{2}+y_{2} I$ be two neutrosophic numbers, the operational relations of neutrosophic numbers are given by Smarandache [30-32] as

$$
\begin{aligned}
N_{1}+N_{2} & =x_{1}+x_{2}+\left(y_{1}+y_{2}\right) I, \\
N_{1}-N_{2} & =x_{1}-x_{2}+\left(y_{1}-y_{2}\right) I, \\
N_{1} \times N_{2} & =x_{1} x_{2}+\left(x_{1} y_{2}+y_{1} x_{2}+y_{1} y_{2}\right) I, \\
N_{1}^{2} & =\left(x_{1}+y_{1} I\right)^{2}=x_{1}^{2}+\left(2 x_{1} y_{1}+y_{1}^{2}\right) I, \\
\frac{N_{1}}{N_{2}} & =\frac{x_{1}+y_{1} I}{x_{2}+y_{2} I}=\frac{x_{1}}{x_{2}}+\frac{x_{2} y_{1}-x_{1} y_{2}}{x_{2}\left(x_{2}+y_{2}\right)} \cdot I, \quad \text { for } x_{2} \neq 0 \text { and } x_{2} \neq-y_{2}, \\
\sqrt{N_{1}} & =\sqrt{x_{1}+y_{1} I}=\left\{\begin{array}{l}
\sqrt{x_{1}}-\left(\sqrt{x_{1}}+\sqrt{x_{1}+y_{1}}\right) I \\
\sqrt{x_{1}}-\left(\sqrt{x_{1}}-\sqrt{x_{1}+y_{1}}\right) I \\
-\sqrt{x_{1}}+\left(\sqrt{x_{1}}+\sqrt{x_{1}+y_{1}}\right) I \\
-\sqrt{x_{1}}+\left(\sqrt{x_{1}}-\sqrt{x_{1}+y_{1}}\right) I
\end{array}\right.
\end{aligned}
$$


However, the above operations may have potential conflicts with those operations for interval numbers. For example, assume that two neutrosophic numbers are $N_{1}=$ $3+2 I$ and $N_{2}=4+3 I$, where $I \in[2,3]$. Then, they are equivalent to two interval numbers $N_{1}=[7,9]$ and $N_{2}=[10,13]$, respectively. According to the multiplication of neutrosophic numbers, one has

$$
\begin{aligned}
N_{1} \times N_{2} & =3 \times 4+(3 \times 3+2 \times 4+2 \times 3) I \\
& =12+23 I=[58,81] .
\end{aligned}
$$

On the other hand, the following result can be obtained by using the multiplication of interval numbers as

$$
N_{1} \times N_{2}=[7,9] \times[10,13]=[7 \times 10,9 \times 13]=[70,117] \text {. }
$$

Obviously, the results in equations (4) and (5) are different. In order to eliminate such conflicts, we propose some improvement on the multiplication of neutrosophic numbers in this section. In the first place, we define the standard form of a neutrosophic number as

$$
N^{s}=x^{s}+y^{s} I_{s}, \quad I_{s} \in[0,1] .
$$

Accordingly, the multiplication includes the following steps. First, we transform the arbitrary neutrosophic number into its standard form $N^{s}=x^{s}+y^{s} I_{s}$, where $I_{s} \in[0,1]$. For example, the above two neutrosophic numbers $N_{1}=3+2 I$ and $N_{2}=4+3 I(I \in[2,3])$ can be rewrote as $N_{1}^{s}=7+2 I_{s}$ and $N_{2}^{s}=10+3 I_{s}$, respectively. Then, one can obtain

$$
\begin{aligned}
N_{1} \times N_{2} & =N_{1}^{s} \times N_{2}^{s}=7 \times 10+(7 \times 3+2 \times 10+2 \times 3) I_{s} \\
& =70+47 I_{s}=[70,117] .
\end{aligned}
$$

Apparently, the same result is achieved by equations (5) and (7). Therefore, it is important to transform an arbitrary neutrosophic number into its standard form in practice. For an arbitrary neutrosophic number $N=x+y I, I \in\left[z_{1}, z_{2}\right]$, the conversion formula is given as

$$
N^{s}=N=\left(x+y z_{1}\right)+\left(y z_{2}-y z_{1}\right) \cdot I_{s}, \quad I_{s}=[0,1] .
$$

Similarly, the conversion formula between an arbitrary interval number $\left[x_{1}, x_{2}\right]$ and the standard neutrosophic number is expressed as

$$
\left[x_{1}, x_{2}\right]=x_{1}+\left(x_{2}-x_{1}\right) \cdot I_{s}, \quad I_{s}=[0,1] .
$$

Next, we use the proposed standard neutrosophic number to describe the strength data as shown in Tables 5 and 6 . As is well known, the standard deviation $\delta$ in Tables 5 and 6 is a commonly used measure of the degree to which a variable is dispersed around its mean value. Then, the strength data of these recycled concrete cubic specimens can be considered as a set of interval numbers $\left[S_{c}-\delta, S_{c}+\delta\right]$ and $\left[S_{t}-\delta, S_{t}+\delta\right]$. Using equation (9), these interval numbers can be transformed into the standard neutrosophic numbers as

$$
\begin{array}{ll}
{\left[S_{c}-\delta, S_{c}+\delta\right]=\left(S_{c}-\delta\right)+2 \delta \cdot I_{s},} & I_{s}=[0,1] \\
{\left[S_{t}-\delta, S_{t}+\delta\right]=\left(S_{t}-\delta\right)+2 \delta \cdot I_{s},} & I_{s}=[0,1] .
\end{array}
$$

For example, the cubic compressive strength for the specimens with the side length of $100 \mathrm{~mm}$ in Table 5 can be expressed as an interval number [33.51-0.905, $33.51+0.905]$ or a standard neutrosophic number $32.605+1.81 I_{s}$. Table 7 shows all the compressive and tensile strengths of these cubic specimens using the form of standard neutrosophic numbers.

4.2. Improved Size Effect Law. The size effect law denotes the strength-size functional relationship. In this section, the existing size effect laws have been improved in two areas: one is using a new ridge estimation method to compute the fitting coefficients of the formula for size effect law, the other is using the standard neutrosophic number to reflect the indeterminacy. For the compressive strength, the commonly used size effect law is

$$
S_{c}=\varepsilon_{1} d^{-2 / 5}+\varepsilon_{0},
$$

where $d$ is the side length of the concrete cube block $\varepsilon_{0}$ and $\varepsilon_{1}$ are the two constants which can be determined by providing fits to experimental data. For the splitting tensile strength, the common formula of size effect law is

$$
S_{t}=S_{\infty}\left(1+\frac{d_{0}}{d}\right)
$$

where $S_{\infty}$ denotes the nominal strength when the specimen size tends to infinity and $d_{0}$ denotes the characteristic size. Theoretically, $S_{\infty}$ is an independent value of the specimen size. From the point of view of dimensional homogeneity, it is more reasonable to replace the side length $d$ with the side length ratio $r$, wherer is the ratio of the cube specimen size to the minimum size in the experiment, that is, $r=d / d_{\min }$. That is because $r$ is a dimensionless parameter. Then, the size effect law for the compressive strength can be rewritten as

$$
S_{c}=\varepsilon_{1} r^{-2 / 5}+\varepsilon_{0} .
$$

Similarly, the size effect law for the splitting tensile strength is revised as

$$
S_{t}=S_{\infty}\left(1+\frac{r_{0}}{r}\right) .
$$

For a particular size ratio $r$, a unique strength value can be calculated by any one of equations (13) and (14). Generally, the least squares estimate (LSE) [36] is used to obtain the fitting coefficients in equations (13) and (14). However, the ill condition of the equation may lead to serious distortion of the fitting results. To solve this problem, a new ridge estimation method is used to compute the fitting coefficients. Taking equation (13) as an example, the following linear regression model can be obtained from equation (13) with the test data of the specimens as 
TABLE 7: Strength values expressed by the standard neutrosophic numbers ("CS" denotes the compressive strength; "TS" denotes the tensile strength).

\begin{tabular}{lc}
\hline Specimen number & $\begin{array}{c}\text { Strengths expressed } \\
\text { by the standard neutrosophic numbers }\end{array}$ \\
\hline CS-70 & $36.374+20.288 I_{s}$ \\
CS-100 & $32.605+1.81 I_{s}$ \\
CS-150 & $28.456+6.83 I_{s}$ \\
CS-200 & $24.103+10.448 I_{s}$ \\
TS-70 & $3.361+2.298 I_{s}$ \\
TS-100 & $3.152+1.52 I_{s}$ \\
TS-150 & $2.87+1.2 I_{s}$ \\
TS-200 & $2.37+0.872 I_{s}$ \\
\hline
\end{tabular}

$$
A \cdot\{\varepsilon\}=\left\{S_{c}\right\}
$$

$$
\begin{aligned}
A & =\left[\begin{array}{cc}
1 & r_{1}^{-2 / 5} \\
\vdots & \vdots \\
1 & r_{m}^{-2 / 5}
\end{array}\right], \\
\{\varepsilon\} & =\left\{\begin{array}{c}
\varepsilon_{0} \\
\varepsilon_{1}
\end{array}\right\}, \\
\left\{S_{c}\right\} & =\left[\begin{array}{c}
S_{c 1} \\
\vdots \\
S_{c m}
\end{array}\right] .
\end{aligned}
$$

As stated before, LSE is often used for solving equation (15) to obtain the fitting coefficients; that is,

$$
\{\varepsilon\}_{\text {lse }}=B^{-1} \cdot z, \quad B=A^{T} A, z=A^{T} y, z=A^{T} y .
$$

As is well known, LSE is very inaccurate if the coefficient matrix of the equation is ill-conditioned. The ridge estimation (RE) [37-40] method is often used to solve the illconditioned equation. For equation (15), the RE solution is

$$
\{\varepsilon\}_{\mathrm{re}}=(B+\lambda E)^{-1} \cdot z,
$$

where $E$ is the identity matrix and $\lambda$ is the ridge parameter that can be determined by the L-curve method [37-40]. In general, the determination process of ridge parameter requires complex calculation and it is difficult to obtain the optimal ridge parameter. Thus, a new ridge estimation (NRE) method is proposed in this section to solve the ill-posed least squares problem. The main formulas of NRE are derived as follows.

Letting $b_{i j}$ denotes the $(i, j)$ th element in the matrix $B$, one has

$$
B=\left[\begin{array}{cccc}
b_{11} & b_{12} & \cdots & b_{1 n} \\
b_{21} & b_{22} & \cdots & b_{2 n} \\
\vdots & \vdots & \ddots & \vdots \\
b_{n 1} & b_{n 2} & \cdots & b_{n n}
\end{array}\right]
$$

Assume $b_{\max }$ is the maximum value in all the diagonal elements of $B$, that is,

$$
b_{\max }=\max \left(b_{i i}\right), \quad i=1 \sim n .
$$

Then, a new regularization matrix $R$ used in NRE is designed as

$$
R=\varsigma \cdot b_{\max } \cdot\left[\begin{array}{cccc}
2^{\left(b_{11} / b_{\max }\right)-1} & 0 & \cdots & 0 \\
0 & 2^{\left(b_{22} / b_{\max }\right)-1} & \cdots & 0 \\
\vdots & \vdots & \ddots & \vdots \\
0 & 0 & \cdots & 2^{\left(b_{n n} / b_{\max }\right)-1}
\end{array}\right] \text {, }
$$

where $\varsigma$ is an adjustable parameter $(\varsigma \subset[0,0.2])$, which can be adjusted according to the condition number of coefficient matrix $B . \varsigma=0.1$ is used in this work. Finally, the NRE of $\{\varepsilon\}$ can be obtained as

$$
\{\varepsilon\}_{\text {nre }}=(B+R)^{-1} \cdot z .
$$

Compared with RE, the advantages of NRE lie in the following aspects. (1) The complex operation of ridge parameter selection is avoided. (2) The calculation accuracy is further improved by automatically adjusting diagonal elements as shown in equation (21). Using NRE and the data in Tables 5 and 6 , the size effect laws for the compressive and tensile strengths in this experiment can be obtained by data fitting as

$$
\begin{aligned}
& S_{c}=16.03+21.71 \times r^{-2 / 5}, \\
& S_{t}=2.1 \times\left(1+\frac{1.03}{r}\right) .
\end{aligned}
$$

As stated before, the standard neutrosophic number $N^{s}=x^{s}+y^{s} I_{s}$, which consists of a determinate part $x^{s}$ and an indeterminate part $y_{s} I_{s}\left(I_{s} \in[0,1]\right)$, is very suitable for expressing those parameters with indeterminacy in practice. In view of this, we further improve the above size effect laws by using the standard neutrosophic number in order to reflect the indeterminacy in data.

For the compressive strength, letting $\varepsilon_{0}=x_{0}+y_{0} I_{s}$ and $\varepsilon_{1}=x_{1}+y_{1} I_{s}$ be two neutrosophic numbers for $x_{0}, y_{0}, x_{1}, y_{1} \in[0,+\infty)$, equation (13) can be rewritten as

$$
S_{c}=\left(x_{0}+x_{1} r^{-2 / 5}\right)+\left(y_{0}+y_{1} r^{-2 / 5}\right) I_{s} .
$$

For the splitting tensile strength, letting $S_{\infty}=x_{2}+y_{2} I_{s}$ and $r_{0}=x_{3}+y_{3} I_{s}$ be two neutrosophic numbers for $x_{2}, y_{2}, x_{3}, y_{3} \in[0,+\infty)$, equation (14) can be rewritten as

$$
\begin{aligned}
S_{t}= & \left(x_{2}+y_{2} I_{s}\right)\left(1+\frac{x_{3}+y_{3} I_{s}}{r}\right)=x_{2}\left(1+\frac{x_{3}}{r}\right) \\
& +\left(y_{2}+\frac{x_{2} y_{3}+x_{3} y_{2}+y_{2} y_{3}}{r}\right) I_{s} .
\end{aligned}
$$

In equations (25) and (26), the positive constants $x_{0}, y_{0}, x_{1}, y_{1}, x_{2}, y_{2}, x_{3}, y_{3}$ can be determined by the proposed NRE method. Equations (27) and (28) present the results obtained after fitting as

$$
\begin{aligned}
& S_{c}=\left(14.25+18.04 \cdot r^{-2 / 5}\right)+\left(3.57+7.25 \cdot r^{-2 / 5}\right) I_{s}, \\
& S_{t}=\left(1.80+\frac{1.52}{r}\right)+\left(0.60+\frac{1.29}{r}\right) I_{s} .
\end{aligned}
$$

For comparison, Figures 7 and 8 present the fitting curves of size effect laws for the compressive and tensile 


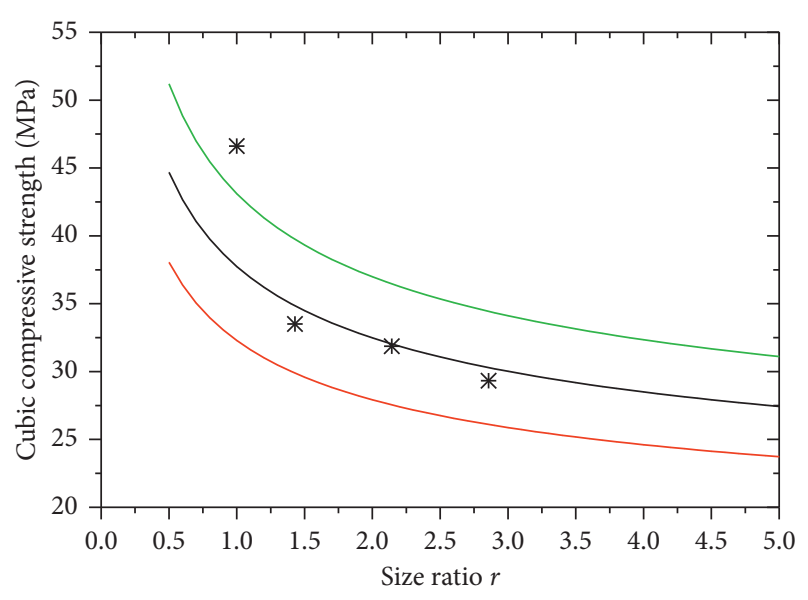

FIGURE 7: Fitting curves of size effect laws for compressive strength.

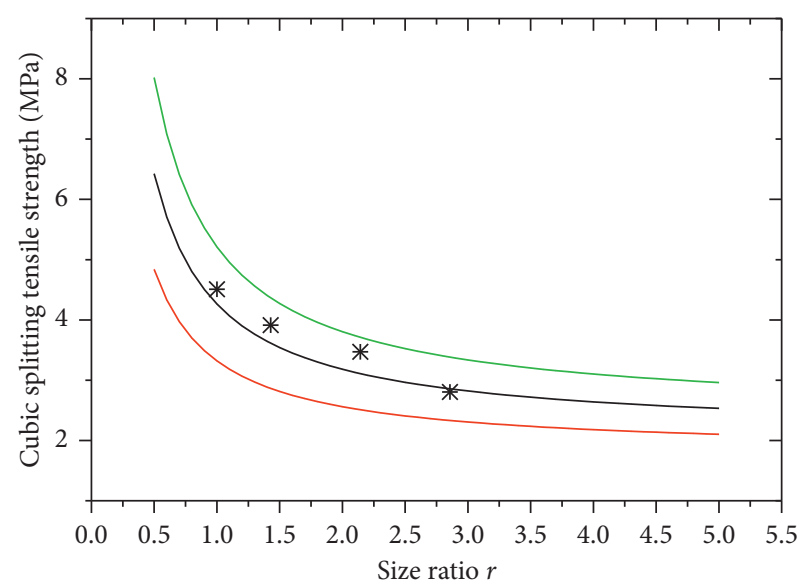

FIGURE 8: Fitting curves of size effect laws for splitting tensile strength.

strengths, respectively. In Figure 7, the black curves and the scatter points indicated by "*" are obtained by equation (23) and the data in the fifth column of Table 5. The red curve and the green curve in Figure 7 indicate the lower boundary and the upper boundary obtained from equation (27). In Figure 8, the black curves and the scatter points indicated by " $*$ " are obtained by equation (24) and the data in the fifth column of Table 6 . The red curve and the green curve in Figure 8 indicate the lower boundary and the upper boundary obtained from equation (28). One can see from Figures 7 and 8 that the size effect laws in the form of the standard neutrosophic number can provide a certain range of the strength value for a particular size. Obviously, the size effect law based on the standard neutrosophic number is more realistic than the existing size effect law.

Comparing equations (12) and (11), one can find that the two size effect formulas for the compressive and tensile strengths seem to be similar. It may be valuable to propose a unified formula of the size effect. In this paper, a unified formula for size effect law is proposed as

$$
S=\delta_{1} d^{-\delta_{3}}+\delta_{0},
$$

where $S$ denotes the physical quantity such as compressive and tensile strengths and $\delta_{0}$ and $\delta_{1}$ are the two constants which can be determined by providing fits to experimental data. $\delta_{3}$ is called the fractal dimension, which is mainly determined by the characteristics of the material itself. $\delta_{3}$ can also be obtained from a large number of test data statistics. In this work, $\delta_{3}=0.4$ is used for the compressive strength and $\delta_{3}=1$ is used for the splitting tensile strength. Equation (29) can be used for other types of size effect laws.

\section{Conclusion}

In this study, four sets of recycled concrete cube specimens with different sizes are produced in the laboratory. The experiments on compressive and tensile strengths are carried out to obtain the rules of the strength value with the change of the specimen size. According to the experimental results, it was found that the compressive and tensile strengths of recycled concrete both have obvious size effects. In general, the strength value decreases gradually with the increase of specimen size. To reflect the uncertainty in the data, a standard neutrosophic number is proposed to improve the multiplication of neutrosophic numbers to a certain degree. Subsequently, the proposed standard neutrosophic number is used for modifying the size effect law on the compressive and tensile strengths. It has been shown that the size effect law based on the neutrosophic number is more realistic than the existing size effect law. The proposed method in this paper provides a simple and effective way to handle the indeterminacy in the testing data and can be extended to other types of size effect laws, which are our future research directions.

\section{Data Availability}

The data used to support the findings of this study are included within the article and also available from the corresponding author upon request.

\section{Conflicts of Interest}

The authors declare that they have no conflicts of interest.

\section{Acknowledgments}

This work was supported by the Natural Science Foundation of China (52078081 and 52008215) and the Natural Science Foundation of Zhejiang Province, China (LQ20E080013), the major special science and technology project (2019B10076) of "Ningbo Science and Technology Innovation 2025."

\section{References}

[1] B. Barhmaiah, M. L. Priyanka, and M. Padmakar, "Strength analysis and validation of recycled aggregate concrete," Materials Today: Proceedings, vol. 37, no. 2, pp. 2312-2317, 2021.

[2] B. Wu and H. Jin, "Compressive fatigue behavior of compound concrete containing demolished concrete lumps," 
Construction and Building Materials, vol. 210, pp. 140-156, 2019.

[3] A.-T. Akono, J. Chen, M. Zhan, and S. P. Shah, "Basic creep and fracture response of fine recycled aggregate concrete," Construction and Building Materials, vol. 266, p. 121107, 2021.

[4] H. Sasanipour, F. Aslani, and J. Taherinezhad, "Chloride ion permeability improvement of recycled aggregate concrete using pretreated recycled aggregates by silica fume slurry," Construction and Building Materials, vol. 270, Article ID 121498, 2021.

[5] C. Zhu, C. Liu, G. Bai, and J. Fan, "Study on long-term performance and flexural stiffness of recycled aggregate concrete beams," Construction and Building Materials, vol. 262, Article ID 120503, 2020.

[6] R. Mi, G. Pan, K. M. Liew, and T. Kuang, "Utilizing recycled aggregate concrete in sustainable construction for a required compressive strength ratio," Journal of Cleaner Production, vol. 276, Article ID 124249, 2020.

[7] J. G. Wang, J. X. Zhang, and D. D. Cao, "Pore characteristics of recycled aggregate concrete and its relationship with durability under complex environmental factors," Construction and Building Materials, vol. 272, Article ID 121642, 2020.

[8] H. Ma and Z. Zhang, "Paving an engineered cementitious composite (ECC) overlay on concrete airfield pavement for reflective cracking resistance," Construction and Building Materials, vol. 252, Article ID 119048, 2020.

[9] Z. Zhang, F. Yang, J.-C. Liu, and S. Wang, "Eco-friendly high strength, high ductility engineered cementitious composites (ECC) with substitution of fly ash by rice husk ash," Cement and Concrete Research, vol. 137, Article ID 106200, 2020.

[10] Z. Zhang, F. Qin, H. Ma, and L. Xu, "Tailoring an impact resistant engineered cementitious composite (ECC) by incorporation of crumb rubber," Construction and Building Materials, vol. 262, Article ID 120116, 2020.

[11] Z. P. Bazant, "Size effect," International Journal of Solids and Structures, vol. 37, pp. 69-80, 2000.

[12] W. Weibull, A Statistical Representation of Fatigue Failures in solids, Elander, Västmanland, Sweden, 1949.

[13] W. Weibull, "A statistical distribution function of wide applicability," Journal of Applied Mechanics, vol. 18, pp. 273277, 1951.

[14] Z. P. Bazant, "Size effect in blunt fracture: concrete, rock, metal," Journal of Engineering Mechanics, vol. 110, no. 4, pp. 518-535, 1984.

[15] Z. P. Bazant, I. M. Daniel, and Z. Li, "Size effect and fracture characteristics of composite laminates," Journal of Engineering Materials and Technology, vol. 118, no. 3, pp. 317-324, 1996.

[16] Z. P. Bazant and J. J. H. Kim, "Size effect in penetration of sea ice plate with part-through cracks. I: theory," Journal of Engineering Mechanics, vol. 124, no. 12, pp. 1310-1315, 1998.

[17] Z. P. Bazant and J. J. H. Kim, "Size effect in penetration of sea ice plate with part-through cracks. II: results," Journal of Engineering Mechanics, vol. 124, no. 12, pp. 1316-1324, 1998.

[18] Z. P. Bažant and Q. Yu, "Universal size effect law and effect of crack depth on quasi-brittle structure strength," Journal of Engineering Mechanics, vol. 135, no. 2, pp. 78-84, 2009.

[19] A. Carpinteri, "Scaling laws and renormalization groups for strength and toughness of disordered materials," International Journal of Solids and Structures, vol. 31, no. 3, pp. 291-302, 1994.

[20] A. Carpinteri and B. Chiaia, "Multifractal scaling law for the fracture energy variation of concrete structures," in Fracture
Mechanics of Concrete Structures, pp. 581-596, Aedificatio Publishers, Freiburg, Germany, 1995.

[21] A. Arslan and R. Ince, "The neural network approximation to the size effect in fracture of cementitious materials," Engineering Fracture Mechanics, vol. 54, no. 2, pp. 249-261, 1996.

[22] Q. W. Yang and S. G. Du, "Prediction of concrete cubic compressive strength using ANN based size effect model," CMC: Computers, Materials, \& Continua, vol. 47, no. 3, pp. 217-236, 2015.

[23] N. Manic, M. Taric, V. Serifi, and A. Ristovski, "Analysis of the existence of size effect on different concrete types," Procedia Technology, vol. 19, pp. 379-386, 2015.

[24] Ç. M. Belgin and S. Şener, "Size effect on failure of overreinforced concrete beams," Engineering Fracture Mechanics, vol. 75, no. 8, pp. 2308-2319, 2008.

[25] Z. P. Bažant, G. Zi, and D. McClung, "Size effect law and fracture mechanics of the triggering of dry snow slab avalanches," Journal of Geophysical Research: Solid Earth, vol. 108, no. 2, 2003.

[26] Z. P. Bažant and S. D. Pang, "Activation energy based extreme value statistics and size effect in brittle and quasibrittle fracture," Journal of the Mechanics and Physics of Solids, vol. 55, no. 1, pp. 91-131, 2007.

[27] Z. P. Bažant, M. Vořechovský, and D. Novák, "Asymptotic prediction of energetic-statistical size effect from deterministic finite-element solutions," Journal of Engineering Mechanics, vol. 133, no. 2, pp. 153-162, 2007.

[28] Z. P. Bažant and Q. Yu, "Designing against size effect on shear strength of reinforced concrete beams without stirrups: I. Formulation," Journal of Structural Engineering, vol. 131, no. 12, pp. 1877-1885, 2005.

[29] P. Grassl and Z. P. Bažant, "Random lattice-particle simulation of statistical size effect in quasi-brittle structures failing at crack initiation," Journal of Engineering Mechanics, vol. 135, no. 2, pp. 85-92, 2009.

[30] F. Smarandache, Neutrosophy: Neutrosophic Probability, Set, and Logic, American Research Press, Rehoboth, NM, USA, 1998.

[31] F. Smarandache, Introduction to Neutrosophic Measure, Neutrosophic Integral, and Neutrosophic Probability, Sitech \& Education Publisher, Columbus, OH, USA, 2013.

[32] F. Smarandache, Introduction to Neutrosophic Statistics, Sitech \& Education Publisher, Columbus, OH, USA, 2014.

[33] J. Ye, "Multiple-attribute group decision-making method under a neutrosophic number environment," Journal of Intelligent Systems, vol. 25, no. 3, pp. 377-386, 2015.

[34] J. Ye, "Fault diagnoses of steam turbine using the exponential similarity measure of neutrosophic numbers," Journal of Intelligent \& Fuzzy Systems, vol. 30, no. 4, pp. 1927-1934, 2016.

[35] Ministry of Construction of China, Test Method Standard for Mechanical Properties of Common Concrete: GB/T 500812002, China Construction Industry Press, Beijing, China, 2003, in Chinese.

[36] Q. W. Yang, "A new biased estimation method based on Neumann series for solving ill-posed problems," International Journal of Advanced Robotic Systems, vol. 16, no. 4, pp. 1-6, 2019.

[37] L. W. Zhang and K. M. Liew, "An improved moving leastsquares Ritz method for two-dimensional elasticity problems," Applied Mathematics and Computation, vol. 246, pp. 268-282, 2014. 
[38] X. Deng, L. Yin, S. Peng, and M. Ding, "An iterative algorithm for solving ill-conditioned linear least squares problems," Geodesy and Geodynamics, vol. 6, no. 6, pp. 453-459, 2015.

[39] A. Zouzias and N. M. Freris, "Randomized extended Kaczmarz for solving least squares," SIAM Journal on Matrix Analysis and Applications, vol. 34, no. 2, pp. 773-793, 2013.

[40] H.-Y. Jun and J.-H. Park, "Generation of optimal correlations by simulated annealing for ill-conditioned least-squares solution," Journal of Nuclear Science and Technology, vol. 52, no. 5, pp. 670-674, 2015. 